\title{
Investigation of Air Drafting Pattern Obtained from the Variation in Outlet Positions inside a Closed Area
}

\author{
B. Tripathi ${ }^{1}$ and S. G. Moulic ${ }^{2}$ \\ ${ }^{1}$ Assistant Professor, 110, School of Engineering, Gautam Buddha University, Greater Noida, 201308,India \\ ${ }^{2}$ Associate Professor, Department of Mechanical Engineering, IIT Kharagpur, Kharagpur, India, 721302
}

Corresponding Author Email: brajeshvbn@yahoo.com

(Received September 17, 2009; accepted October 9, 2011)

\begin{abstract}
The ceiling type diffusers were analyzed for the combinations of inlet streams on outlet locations including the variation of angles at inlet. A detailed analysis has been presented using plots of streamlines, isotherms, heat-lines and variation of the average Nusselt number with changes in buoyancy ratio. The results indicate that the location of outlet plays a significant role in the targeted occupied region and it can be used for different applications of ceiling diffusers. The predicted performance of fluid flow can be applied in different medical clean room applications. The airflow analysis indicates that for a single ceiling air diffuser, it is advantageous to adopt a variation in the inclination angle at inlet to achieve maximum air distribution profiles. The combinations of inlet and outlet position reduce the short-circuiting of supply air, providing additional uniform temperatures and room airflow in the occupied zone.
\end{abstract}

Keywords: Airflow, Ceiling, Diffuser, CFD, Streamlines

\section{INTRODUCTION}

The most important characteristic of airconditioning design is airflow distribution for clean and comfortable environment. Air can be supplied from different locations in a room with the inlet located at horizontal and vertical supply systems. Diffusers can be categorized in straight, inclined, conical, circular and wavy types. The location of the diffuser applied on the floor, side walls and ceiling. For personal use, diffusers are preferred on the side walls whereas for commercial and large scale applications, ceiling type diffusers are selected for the Heating, Ventilation and Airconditioning (HVAC). The present work considers a slightly modified ceiling inlet with various outlet options and flow patterns based comparative study.

Numerous simulation methods were developed based on Patankar's numerical solution procedure to predict the diffusion of isothermal and non-isothermal plane wall jet in enclosed space. In the literature, a room air distribution system is classified into numerical approach and validation system which can be used for the benchmarking of the solution. The implication and validation of the approach using standard numerical procedure for heating and cooling modes was described (Reintarz et al. 1984; Nielsen et al. 1978). The flow within the diffuser and in a vertical plane of the room could be a turbulent flow and predicted by a twodimensional solution (Kato et al. 1985: Awbi et al.1986, 1987). Applicability of different turbulent flow models was accessed for two-dimensional and three- dimensional ventilation studies for finite different method (Awbi, 1989) and low Reynolds number models for wall boundary effect (Patel et al. 1985). A buoyancy flow in a standard cavity for low Reynolds number k- $\varepsilon$ turbulent model (Chen et al. 1990) was analyzed for Boussinesq approximation. The importance and applicability of numerical methods in room air distribution system for ceiling type diffusers was investigated just after the top mounted diffuser system.

The variation in the flow direction with supply diffuser and exit sequences for contamination diffusion with airflow patterns was predicted (Murakami et al. 1989; Nielsen, 1990). Unsteady treatment for the room disinfected particles with single supply and exit options was used (Lage et al. 1991, 1992) for single and multi room configuration ( $\mathrm{Li}$ et al. 1991). A more ventilation related application was solved for classroom analysis for increasing number of inlet/outlet with related positions (Chen et al., 1992; Kato et al. 1992) and for benchmark solution of laminar flow (Davidson et al. 1998). Heat transfer model involving all modes of the transfer viz., convection, conduction and radiation was also studied in the presence of heat source in room geometries (William et al.1994a, 1994b; Hsu et al. 1997; Calmidi et al., 1998; Gladstone et al., 2000, 2001; Xu et al. , 2001a, 2001b; Sun et al. , 2004). A two-dimensional CFD analysis was presented for the indoor environment for the cool air distribution ( $\mathrm{Hu}$ et al. 1999), warn air distribution (Sinha et al. 2000) and visualization by contour and vector plots in virtual 
simulation (Svidt et al. 2001). Sub-grid model for the air velocity profiles on contaminated indoor environment was also discussed ( $\mathrm{Su}$ et al. 2001), air changes rates for particle removal efficiency in livestock building (Einberg et al. 2003), surgical operating theater (Kameel et al. 2004) and for under floor air distribution system (Lin et al. 2004).

$$
\begin{gathered}
P=\frac{\bar{p}}{\rho_{0}^{2}}, \theta=\frac{T-T_{0}}{T_{w}-T_{0}}, \quad C=\frac{\bar{c}-c_{0}}{q_{s} W_{1} / U_{0}}, \quad \tau=\frac{\bar{\tau}}{W_{1} / U_{o}}, \quad i^{*}=\frac{t}{W_{1} / U_{o}}, \\
k^{*}=\frac{k}{U_{0}^{2}}, \quad \varepsilon^{*}=\frac{\varepsilon}{U_{0}^{2} / W_{1}}, \quad \mu_{T}^{*}=\frac{\mu_{t}}{\mu},
\end{gathered}
$$

Airflow, temperature and concentration profiles were discussed for ventilation system in an office room (Lin et al. 2011; Lim et al. 2009), multi room building (Kao et al. 2009) and in hospital (Mentdez et al. 2008) through turbulent model and validated with experimental results. CFD boundary condition was also discussed for indoor environment around human occupants (Srebric et al. 2008) and VOC contamination affect on air curtain (Aubert et al. 2011). The validation of various turbulent flow models was presented by Zhang et al. (2007).

The objective of this work is to apply the low Reynolds number turbulent model on ceiling diffuser for room airflow configuration. The governing equation of fluid flow is solved in a room assembled with a ceiling diffuser to analyze the combined effect of inlet-outlet configuration on the airflow patterns. The location of air inflow was also varied to discuss another prospect of this analysis.

\section{FLOW FORMULATION}

The formulation of airflow is initiated with the preliminary analysis with laminar flow and detailed analysis with low Reynolds number turbulent flow model. The Reynolds averaged form of Navier-Stokes equation is used to solve various conservative equations. To solve momentum equation, the Reynolds analogy is used while turbulent Prandtl number is used in the energy equation. It has been proved from the various turbulent flow experiments that the turbulent Prandtl number and Schmidt number are minimum near the flow boundaries. Various researchers use these nondimensional numbers to predict the flow features more accurately around the boundaries and the numbers are selected as their respective values in the current work (Abe et al.1995). Non-dimensional number offers a great flexibility to reduce number of variables to the optimum number and the following variables are used in the governing equation of the fluid flow. The inlet velocity and inlet width are used as a characteristics velocity and length respectively.

The steady, density independent non-dimensional form of fluid flow conservation equations for continuity, momentum, energy, concentration and mean age can be written as:

$$
\begin{aligned}
& \frac{\partial U_{1}}{\partial X_{1}}+\frac{\partial U_{2}}{\partial X_{2}}+\frac{\partial U_{3}}{\partial X_{3}}=0 \\
& \frac{\partial}{\partial X_{j}}\left\langle U_{j} U_{i}\right)=-\frac{\partial P}{\partial X_{i}}+\frac{\partial}{\partial X_{j}}\left(\left(\frac{1}{\operatorname{Re}}+\frac{\mu^{T}}{\operatorname{Re}}\right)\left(\frac{\partial U_{i}}{\partial X_{j}}+\frac{\partial U_{j}}{\partial X_{i}}\right)\right)+\frac{G r}{\operatorname{Re}^{2}} \theta \delta_{i, 2} \\
& \frac{\partial\left(U_{1} \theta\right)}{\partial X_{1}}+\frac{\partial\left(U_{2} \theta\right)}{\partial X_{2}}+\frac{\partial\left(U_{3} \theta\right)}{\partial X_{3}}=\frac{\partial}{\partial X_{j}}\left(\left(\frac{1}{\operatorname{RePr}^{2}}+\frac{\mu_{T}}{\operatorname{ReP}_{\mathrm{T}}}\right) \frac{\partial \theta}{\partial X_{j}}\right) \\
& \frac{\partial\left(U_{1} C\right)}{\partial X_{1}}+\frac{\partial\left(U_{2} C\right)}{\partial X_{2}}+\frac{\partial\left(U_{3} C\right)}{\partial X_{3}}=\frac{\partial}{\partial X_{j}}\left(\left(\frac{1}{\operatorname{ReSc}}+\frac{\mu_{T}}{\operatorname{ReSc} \mathrm{T}}\right) \frac{\partial C}{\partial X_{j}}\right)+S_{C}^{*} \\
& \frac{\partial\left(U_{1} \tau\right)}{\partial X_{1}}+\frac{\partial\left(U_{2} \tau\right)}{\partial X_{2}}+\frac{\partial\left(U_{3} \tau\right)}{\partial X_{3}}=\frac{\partial}{\partial X_{j}}\left(\left(\frac{1}{\operatorname{Re} S C}+\frac{\mu_{T}}{\operatorname{Re~Sc} \mathrm{T}}\right) \frac{\partial \tau}{\partial X_{j}}\right)+1
\end{aligned}
$$

LRE (Lam-Bremhorst, 1981) k- $\varepsilon$ model is used to close the RANS equations with the following values of the dimensionless numbers; $\mathrm{Sc}=1.0 ; \mathrm{Pr}=0.7 ; \mathrm{Sc}_{\mathrm{t}}=0.7$; $\operatorname{Pr}_{\mathrm{t}}=0.8 ; \mathrm{A}_{\mu}=0.0165 ; \mathrm{A}_{\mathrm{t}}=20.5 ; \mathrm{AC}_{1}=0.05$.

The computational domain is presented in Fig. 1.(two dimensional), which has four walls, left, right, top and bottom walls (each wall has dimension of $4 \mathrm{~m}$ ) with inlet $(0.2 \mathrm{~m})$ located on right side of the top wall, while outlet $(0.2 \mathrm{~m})$ is located on the right side wall (Case I). In the Fig. 1(b) \& (c), the location of inlet is fixed while the location of outlet is varied on the left side wall (Case II) and on the top wall (Case III) of the room.

The room geometry (Tripathi et al. 2004, 2005) of top mounted ceiling type is divided into series of vanes as shown in the enlarged part of Fig. 1(a). The inlet measurement of $0.2 \mathrm{~m}$ is separated into 12 equal intervals, where first angle is considered as $5.5^{\circ}$. Other parts of the division is increased in angle $(\psi), \psi_{\mathrm{n}+1}=$ $\psi_{\mathrm{n}}+5.5^{0}$, where $\mathrm{n}=0,1 \ldots 11$. The temperature of incoming air is considered lower than the walls of the room. The Boundary conditions at outlet, inlet and solid walls are presented in Table 1. Boundary conditions are specified at wall as no-slip boundary condition. The turbulent transport quantities and governing components of velocities and temperature at inlet boundary are specified from the data obtained experimentally and by simulation from initial distribution. Inflow boundary condition is specified at inlet and the variable component at inflow is assumed to be uniform as shown in Table 1. The value of inlet velocity in Y-direction is assumed to be zero while consideration has been given to the velocity components with different values of the inclination angle. At the walls no-slip $\left(\mathrm{U}_{1}=\mathrm{U}_{2}=\mathrm{U}_{3}=0, \theta=1\right)$ is preferred as normal velocity used for the velocity components in $\mathrm{X}, \mathrm{Y}$ and $\mathrm{Z}$ direction. Outflow boundary condition was specified at outlet. The Neumann $(\delta \varphi / \delta n$ $=0$ ) type is defined for the flow variable at outlet. To solve overall mass conservation, the outlet profiles are iteratively corrected. The Neumann boundary condition is used to define the mean age and concentration as presented in Table 1. 


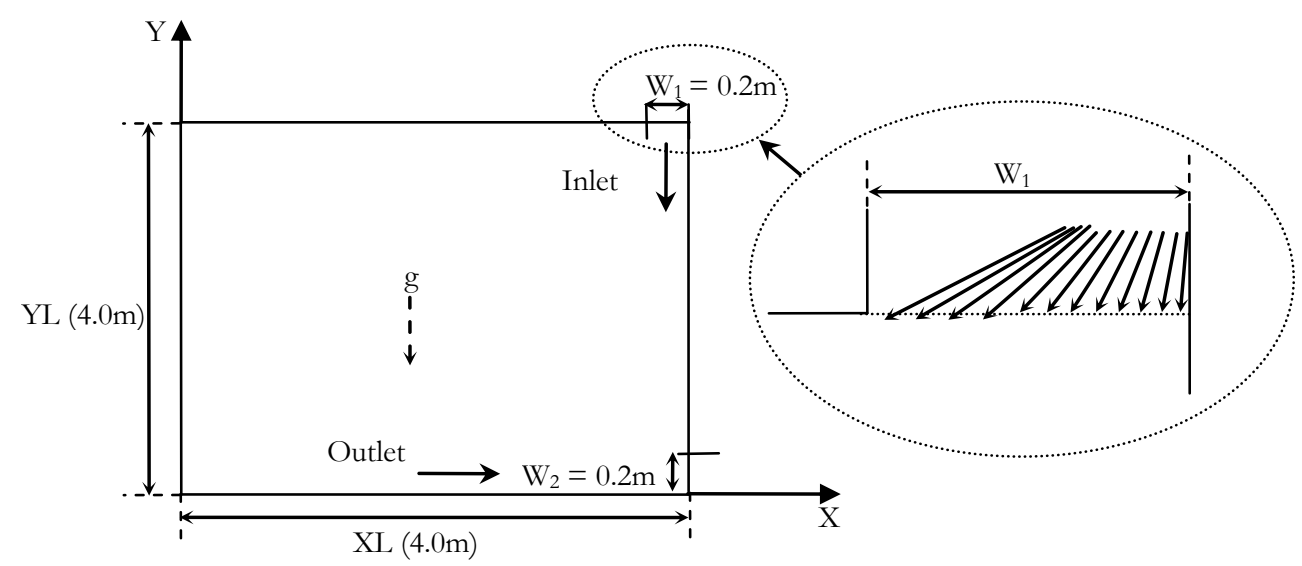

(a) Room geometry showing outlet on the right wall (Case I)

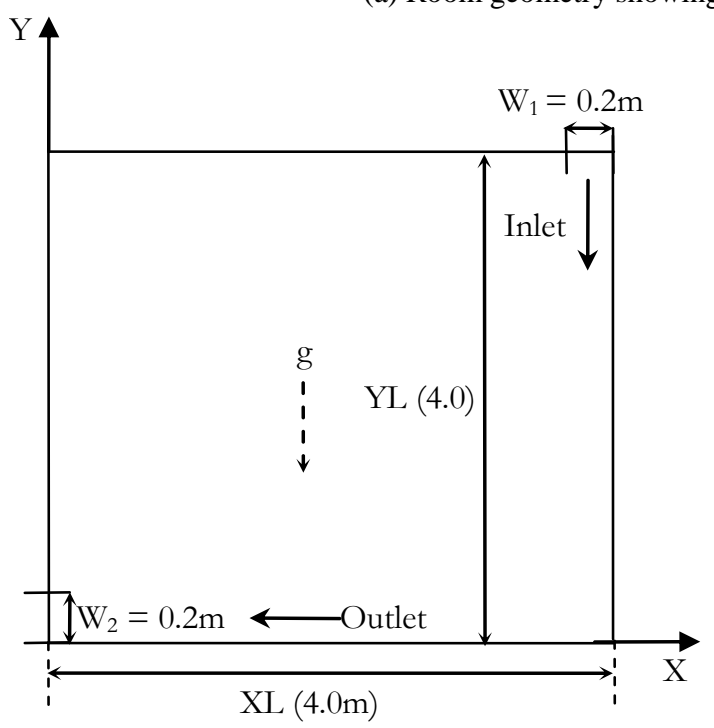

(b) Outlet on the left wall (Case II)

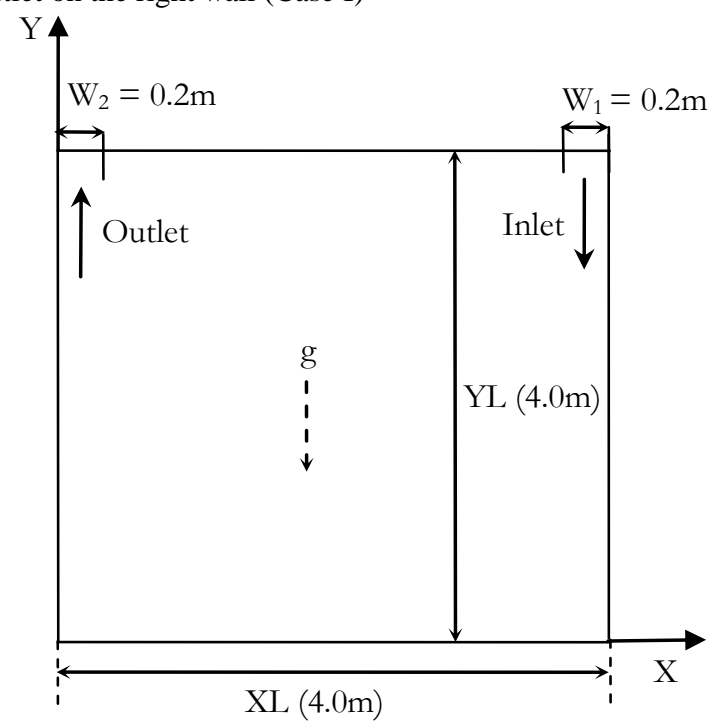

(c) Outlet on the top wall (Case III)

Fig. 1. Schematic of case I, II and II showing inlet position on top right side of ceiling (all dimensions are in $\mathrm{m}$ )

Table 1 Wall, inlet and outlet conditions for boundary

\begin{tabular}{|c|c|c|c|c|}
\hline Variable & \multicolumn{2}{|c|}{ Laminar flow } & \multicolumn{2}{c|}{$\begin{array}{c}\text { Turbulent flow LRE } \\
\text { (Low Reynolds } \\
\text { number) model }\end{array}$} \\
\hline & Wall & Inlet & Wall & Inlet \\
\hline $\mathrm{U}_{1}$ & 0 & 1 & 0 & 1 \\
\hline $\mathrm{U}_{2}$ & 0 & 0 & 0 & 0 \\
\hline $\mathrm{U}_{3}$ & 0 & 0 & 0 & 0 \\
\hline$\theta$ & 1 & 0 & 1 & 0 \\
\hline $\mathrm{k}$ & - & - & 0 & 0.005 \\
\hline$\varepsilon$ & - & - & $\frac{2 \mathrm{k} / \mathrm{Re} \mathrm{Y}_{\mathrm{P}}^{2}}{\mathrm{~K}}$ & $\mathrm{~K}^{1.5} / \mathrm{W}_{1}$ \\
\hline $\mathrm{C}$ & $\frac{\partial C}{\partial n}=0$ & 0 & $\frac{\partial C}{\partial n}=0$ & 0 \\
\hline$\tau$ & $\frac{\partial \tau}{\partial n}=0$ & 0 & $\frac{\partial \tau}{\partial n}=0$ & 0 \\
\hline
\end{tabular}

The width of inlet and outlet slots on z-axis is assumed to be extending throughout the width of the room; therefore the flow is treated as two-dimensional. All the walls are assumed to be at constant temperature, except inlet and outlet ports. The non-dimensional form of the various conservative equations along with the boundary condition is integrated with finite volume approach with SIMPLEC algorithm (Patankar, 1980; Van-Doormaal et a.l., 1984). A FORTRAN program is written on the IBM Linux server of the institute for simulations.

\section{RESUlts AND DiscusSiON}

The sets of various grid points (from 40 to 220 grid points) in each direction have been tested and validated with the standard solution of driven cavity. A table (Table 2) is presented to analysis the grid independence test for centerline velocity. The difference between centerline velocity of grid points 81 and 101 is less than that of between grid points of 61 and 81 . Therefore a set of $81 \times 81$ grid points has been adopted in $\mathrm{X} \& \mathrm{Y}$ direction respectively. All the grid points follow the standard power law scheme in the coarser areas of the room. 
The buoyancy ratio (ratio of Grashof number to Reynolds number) has been varied for Reynolds number, $R e=1000,2000,5000$ and 8000 respectively. All the residuals of the governing quantities are less than $10^{-5}$ hence assumed to be converged. The nondimensional length of 20 (Dimensional length $(4.0 \mathrm{~m}) /$ inlet width $(0.2 \mathrm{~m})=20)$ is used for plotting streamlines, isotherms and Bejan's heat lines (Kimur et al, 1983). A numerical solution was obtained to compare the results with the standard and experimental results (Nielsen, 1990). The numerical values are in good agreement with the reported experimental data.

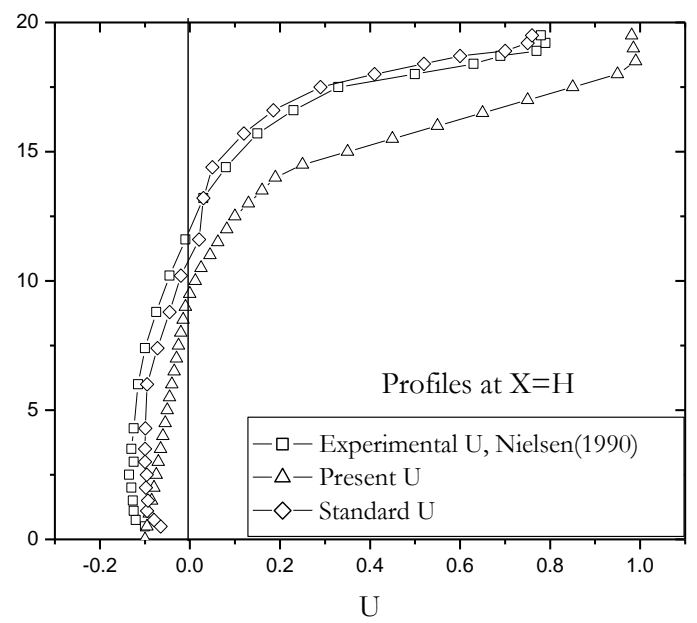

(a) Dimensionless velocity, $\mathrm{U}$

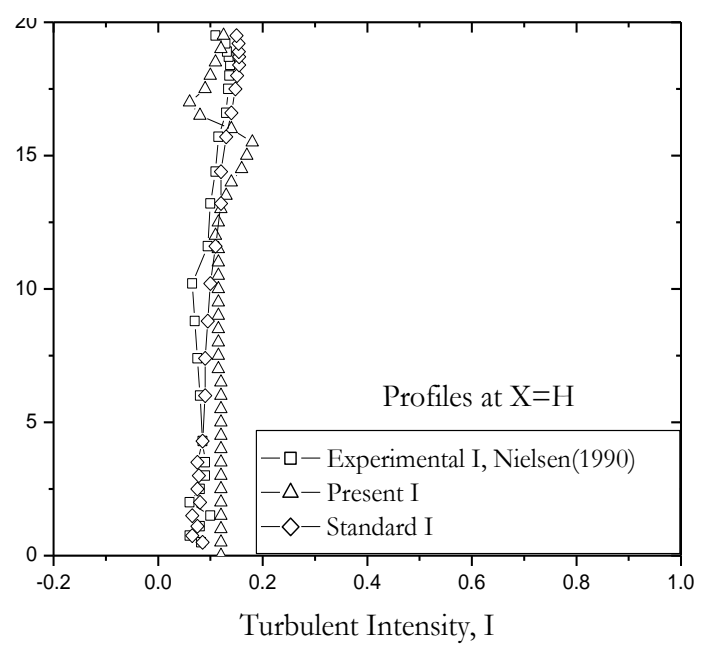

(b) Turbulence intensity, I

Fig. 2. Computed and measured dimensionless velocity and turbulence intensity at section $\mathrm{x} / \mathrm{H}=1$
Table $2 \mathrm{~V}$-velocity along the horizontal centerline, at $\mathrm{Re}=400$ and three set of grid points

\begin{tabular}{|c|c|c|c|c|}
\hline \multirow{2}{*}{$\begin{array}{c}\text { Reynolds } \\
\text { number }\end{array}$} & \multirow{2}{*}{$\begin{array}{c}\text { Buoyancy } \\
\text { ratios }\end{array}$} & \multicolumn{3}{|c|}{$\begin{array}{c}\text { Values of the centerline } \\
\text { velocity }\end{array}$} \\
\cline { 2 - 5 } & & 61 & 81 & 101 \\
\hline \multirow{4}{*}{100} & 0.2 & 0.35 & 0.41 & 0.42 \\
\cline { 2 - 5 } & 0.4 & 5.711 & 2.131 & 1.932 \\
\cline { 2 - 5 } & 0.6 & 7.155 & 2.789 & 2.346 \\
\cline { 2 - 5 } & 0.8 & 8.155 & 3.439 & 3.245 \\
\cline { 2 - 5 } & 1.0 & 9.201 & 5.2958 & 4.897 \\
\hline \multirow{4}{*}{400} & 0.2 & 6.785 & 1.9717 & 1.784 \\
\cline { 2 - 5 } & 0.4 & 7.352 & 2.3801 & 1.992 \\
\cline { 2 - 5 } & 0.6 & 8.653 & 3.1227 & 2.875 \\
\cline { 2 - 5 } & 0.8 & 10.295 & 4.2040 & 3.912 \\
\cline { 2 - 5 } & 1.0 & 13.456 & 6.9092 & 5.815 \\
\hline
\end{tabular}

Figure 3(a) to Fig. 3(d) show the plots of streamline contours and isotherms for $\mathrm{Re}=2000$ and buoyancy ratios of $0.1,0.5$. The cold air stream enters the room at various angles as shown in streamline plots of Fig. 3(a) at buoyancy ratio of 0.1 . The streamlines near the left edge of the inlet attach with the ceiling, move along the ceiling, stoop down along the left wall, then move along the floor and leave through the exit. One small vortex is observed near the outlet adjacent to the right wall. Comparison of Fig. 3(a) and Fig. 3(c) for buoyancy ratio of 0.1 and 0.5 respectively reveals that the streamline pattern in Fig. 3(c) shows small vortex formed near the top left corner and bottom left corner of the room.

Isotherms are plotted in Fig. 3(b) and Fig. 3(d) to study the effect of increase in inertia on temperature distribution. Isotherms shown in Fig. 3 (b), at buoyancy ratio of 0.1 , indicates the variation in temperature of the occupied region inside the room. Figure 3 (d) indicates that at a higher buoyancy ratio of 0.5 , the temperature variation is confined to a narrow region in thermal boundary layers near the wall.

Heat-lines are plotted in Fig. 4, at $\mathrm{Re}=1000$ and 2000 and buoyancy ratios of 0.1 and 1.0. A glance at figures reveals that the pattern of heat-lines is similar in nature to the corresponding streamlines. This indicates that energy is mainly transported by convection, along streamlines. The average Nusselt number on the right and left walls for different buoyancy ratios is given in Table 3. It can be observed from the table that the average Nusselt number increases with increase in the buoyancy ratio. 
B. Tripathi et al. / JAFM, Vol. 5, No. 4, pp. 1-12, 2012.

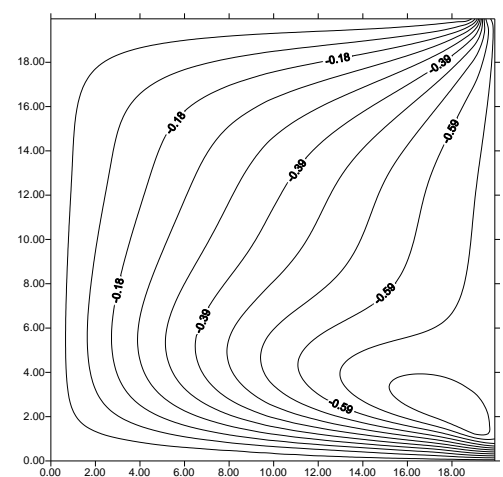

(a) Streamlines for buoyancy ratio $=0.1$

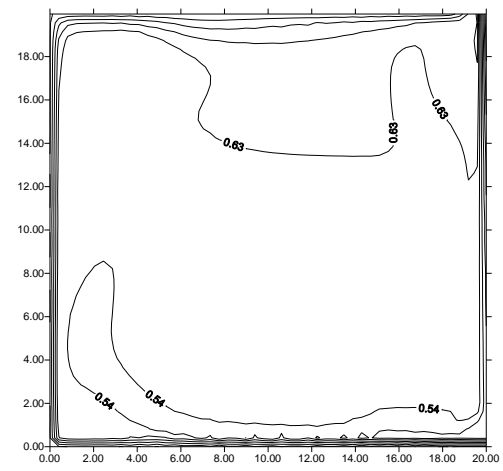

(b) Isotherms for buoyancy ratio $=0.1$

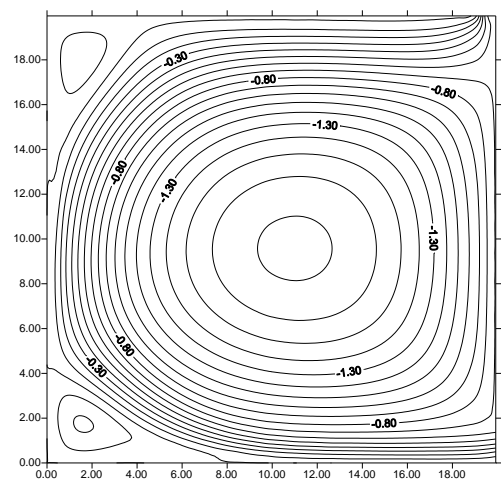

(c) Streamline for buoyancy ratio $=0.5$

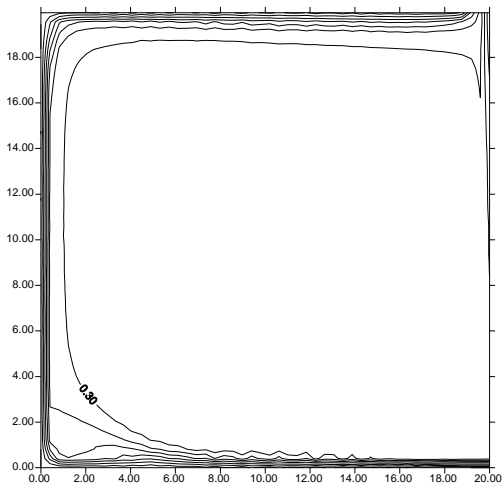

(d) Isotherms for buoyancy ratio $=0.5$

Fig. 3. Streamlines and isotherms for Case $I$ at $R e=2000$

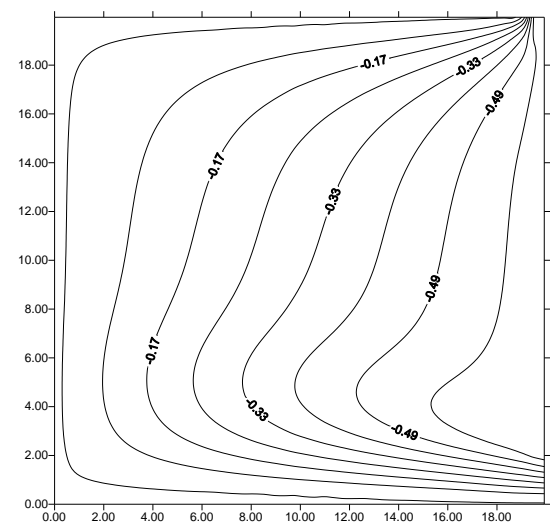

(a) Heat-lines at buoyancy ratio $=0.1$

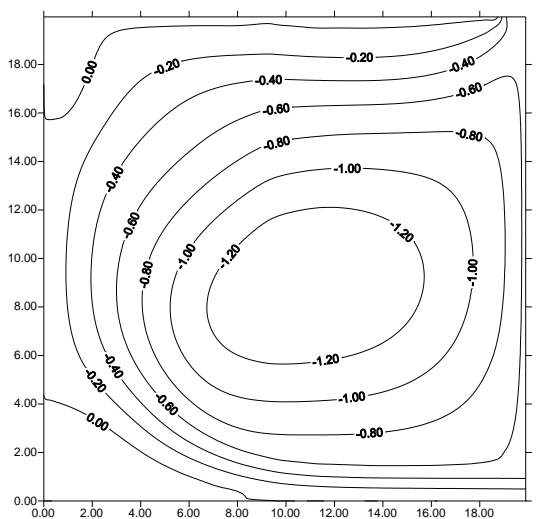

(b) Heat-lines at buoyancy ratio $=1.0$

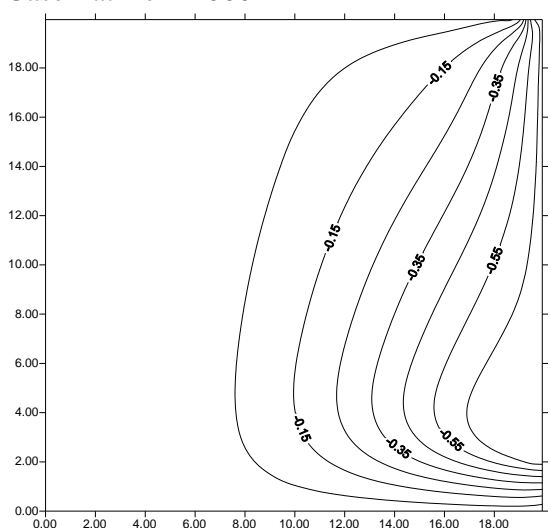

(c) Heat-lines at buoyancy ratio $=0.1$

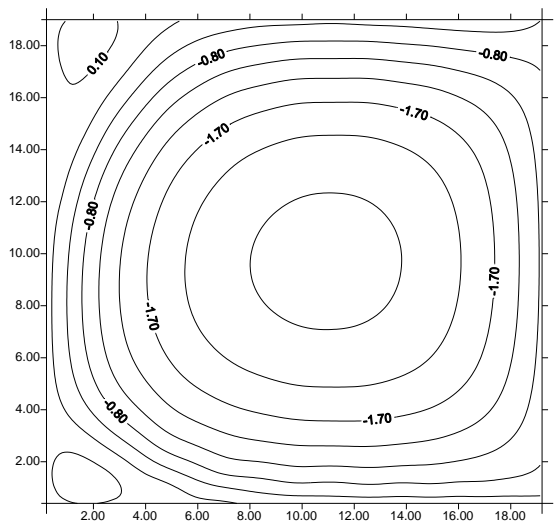

(d) Heat-lines at buoyancy ratio $=1.0$

Fig. 4. Heat-lines for Case $I$ at $\operatorname{Re}=1000(a$ and $b$ ) and $\operatorname{Re}=2000$ (c and d) 
Table 3 Average values of Nusselt numbers at different buoyancy ratios for Case I

\begin{tabular}{cccc}
\hline $\begin{array}{c}\text { Reynolds } \\
\text { number }\end{array}$ & $\begin{array}{c}\text { Buoyancy } \\
\text { ratios }\end{array}$ & $\begin{array}{c}\text { Nusselt } \\
\text { number } \\
\text { at right } \\
\text { wall }\end{array}$ & $\begin{array}{c}\text { Nusselt } \\
\text { number } \\
\text { at left } \\
\text { wall }\end{array}$ \\
\hline \multirow{4}{*}{1000} & 0.1 & 4.51684 & 1.63135 \\
& 0.5 & 5.71105 & 2.13123 \\
& 1.0 & 7.15585 & 2.78948 \\
& 1.5 & 8.15554 & 3.43998 \\
2000 & 2.0 & 9.20147 & 5.2958 \\
\hline & 0.1 & 6.7858 & 1.9717 \\
& 0.5 & 7.3529 & 2.3801 \\
& 1.0 & 8.6539 & 3.1227 \\
& 1.5 & 10.295 & 4.2040 \\
& 2.0 & 13.456 & 6.9092 \\
\hline
\end{tabular}

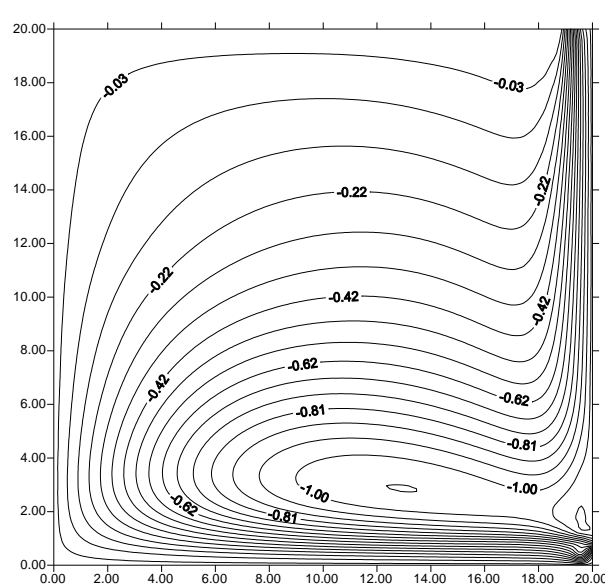

(a) Streamlines at $\operatorname{Re}=5000$

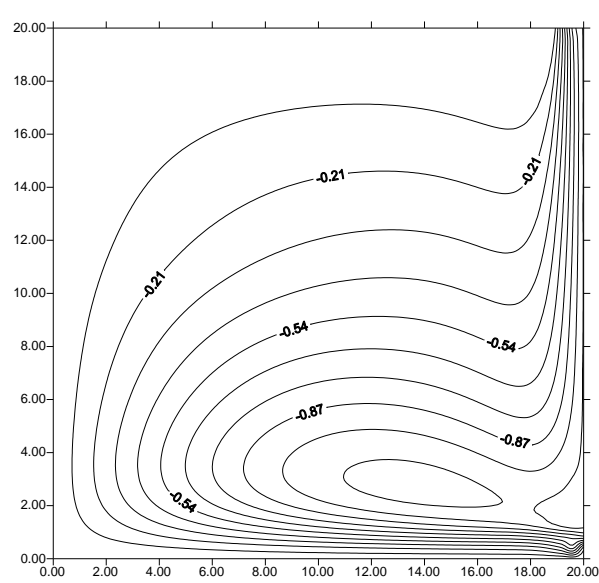

(c) Streamlines at $\mathrm{Re}=8000$
The mean flow streamlines and mean isotherms are shown in Fig. 5(a) and Fig. 5(d) respectively, for $\mathrm{Re}=5000,8000$ and buoyancy ratio of 0.1 . Figure 5(a) indicates that the mean-flow streamlines originating from the right edge of the inlet have a tendency to move downwards along the right wall, towards the outlet located near the bottom of the right wall. The meanflow streamlines originating from the left edge of the inlet move along the ceiling, left wall and floor, and go out through the exit. The mean isotherm plots show a slight decrease in the temperature values as shown in Fig. 5(d), for $\operatorname{Re}=5000$ and buoyancy ratio of 0.1 .

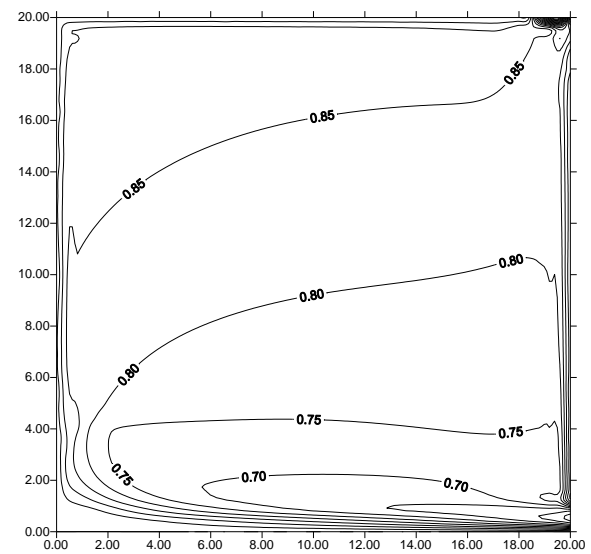

(b) Isotherms at $\mathrm{Re}=5$

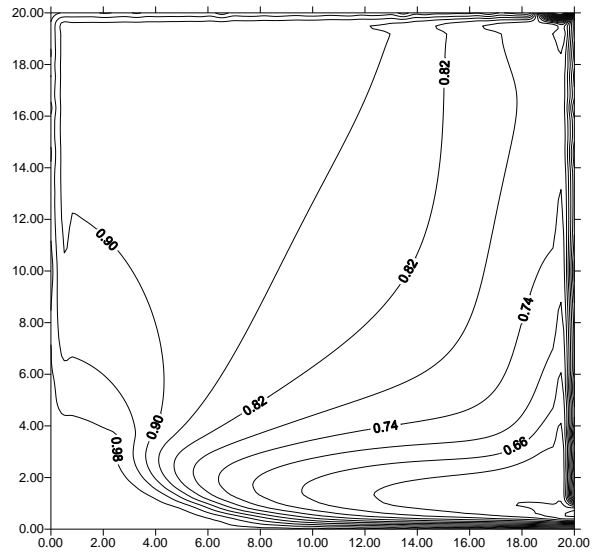

(d) Isotherms III at $\mathrm{Re}=8000$

Fig. 5. Mean-flow streamlines and mean isotherms for Case I at buoyancy ratio $=0.1$

The mean-flow streamlines and mean isotherms are shown in Fig. 5(c) and Fig. 5(d) respectively for $\mathrm{Re}=8000$ and buoyancy ratio of 0.1 . The mean streamline contours in Fig. 5(c) shows that the increase in Reynolds number does not affect the airflow patterns significantly. Comparison of Fig. 5(a) and Fig. 5(c) indicates that the main air-stream progress comparatively long distance due to its high inertia. The mean isotherm plot in Fig. 5(d) indicates the temperature variation throughout the occupied zone.

Now, the outlet is shifted from the bottom of right wall to the bottom of left wall in case II. Other dimensions and position of the inlet are the same as in Case I. The motivation behind this configuration is to visualize the effect on airflow patterns for diagonally cornered inlet 
and outlet position. Such arrangement may be useful for some specific situations where rapid and instant cooling is required. Results of laminar flow simulation for Case II have been presented for Reynolds number, $\mathrm{Re}=2000$ and buoyancy ratio of 0.1 . The streamlines shown in Fig. 6(a) indicate that the main air stream split into two streams after entering the room from the right edge of the ceiling. The streamlines originating from the right edge of the inlet move downwards along the right wall, then along the floor and leave through the exit located at the bottom of the left wall. The streamlines originating from the left edge of the inlet attach with the ceiling due to Coanda effect. A large clockwise rotating re-circulation region is formed in the upper central portion of the room. The figure indicates that there are two counter-rotating vortices inside the room. The isotherms in Fig. 6(b), for $\mathrm{Re}=2000$ and buoyancy ratio of 0.1 , indicate a very slight temperature variation throughout the occupied zone.

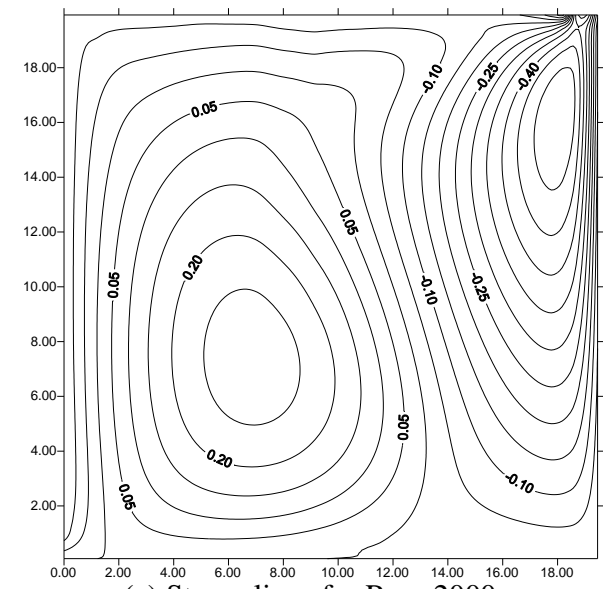

(a) Streamlines for $\mathrm{Re}=2000$

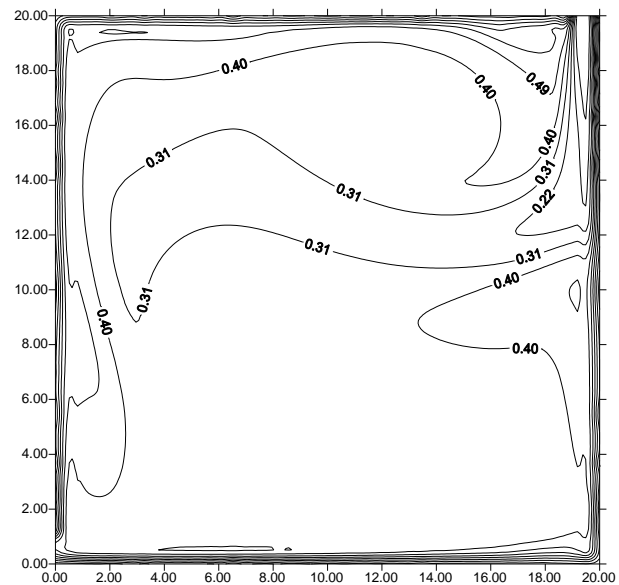

(b) Isotherms for $\mathrm{Re}=2000$

Fig. 6. Streamlines and isotherms for Case II at buoyancy ratio $=0.1$

In order to obtain a heat transfer phenomena inside the room, the heat-lines for $\mathrm{Re}=1000$ and 2000 at buoyancy ratio of 0.1 are shown in Fig. 7(a) and Fig. 7(b) respectively. Comparison of the heat-lines of Fig. 7(b) with the streamline patterns in Fig. 6(a) reveals that the heat-line pattern is similar to the streamline pattern. Figure 8 presents the variation of the maximum mean velocity in $\mathrm{X}$-direction with buoyancy ratio for
Reynolds number, $\mathrm{Re}=5000$ and 8000 respectively. An increase in the velocity is observed with the increase in buoyancy ratio.

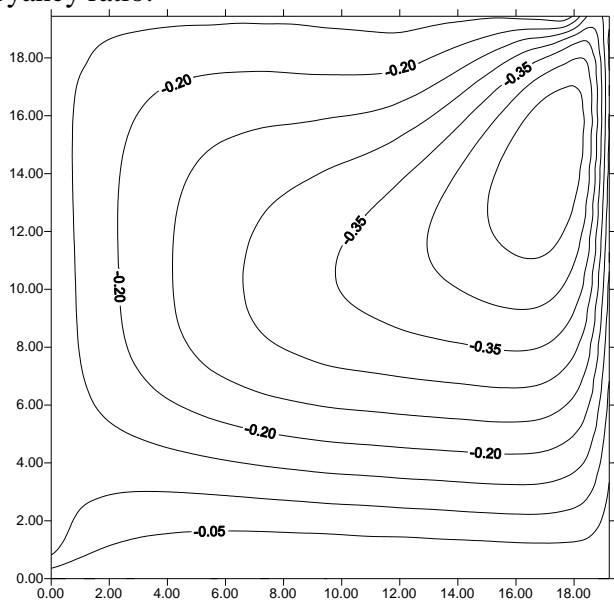

(a) Heat-lines for $\mathrm{Re}=1000$

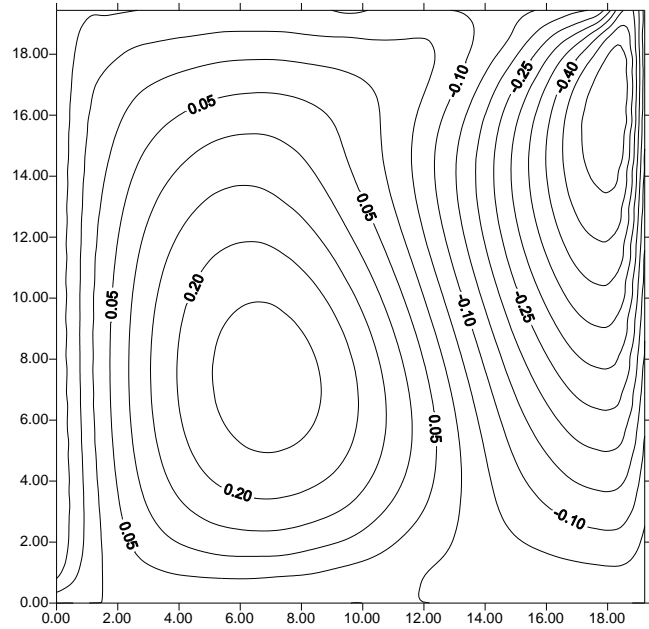

(b) Heat-lines for $\mathrm{Re}=2000$

Fig. 7. Heat-lines for Case II at buoyancy ratio $=0.1$

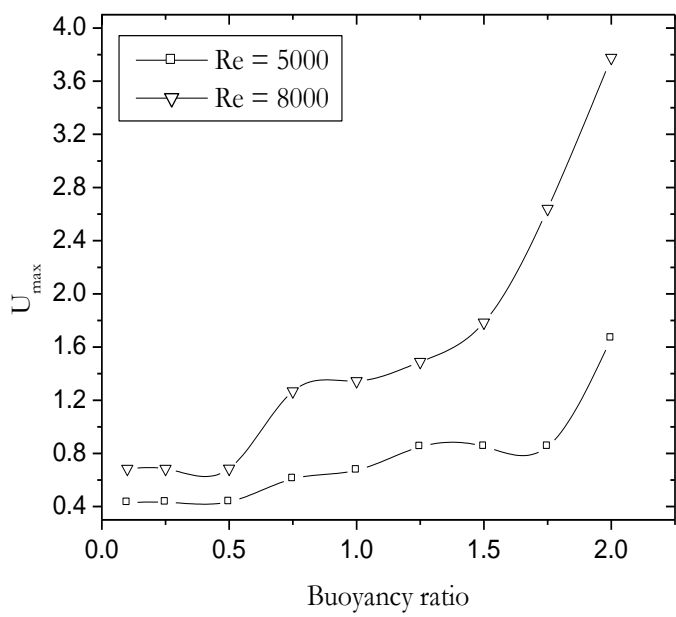

Fig. 8. Variation of the maximum $X$-velocity with buoyancy ratio for Case II

Figure 9(a), Fig. 9(b) and Fig. 9(d) show the streamlines, isotherms and heat-lines at $\mathrm{Re}=2000$ and buoyancy ratio of 0.1 . Figure 9 (a) indicates the attachment of inlet cold air stream with the ceiling for a 
short distance. Then it goes vertically downwards in the middle of the enclosure, touches the left wall then goes out through outlet. A dense clockwise rotating vortex is seen in the upper central part of the room. A counterclockwise vortex is observed below the main air-jet, occupying a large portion of the region near the floor. Figure 9(b) shows that the temperature variation is largely confined to the thermal boundary layers near the right and left walls. The heat lines in Fig. 9(d) indicate that the cold air stream enters the room and exchanges energy. The heat lines have higher values in the center of the room while lower values in the occupied region. The heat-line pattern in Fig. 9(d) is similar in nature to the streamline pattern in Fig. 9(a). This indicates that energy is transported inside the room mainly by convection along the streamlines.

Figure 9(c) shows the heat-lines at $\mathrm{Re}=2000$ for buoyancy ratio $=0.1$. It shows that the small vortix near the bottom region near the floor. The size of the clockwise-rotating vortex in the upper central part of the room reduces considerably in size with the increase in the buoyancy ratio to 0.5 (Fig. 9(d)). The uniformity

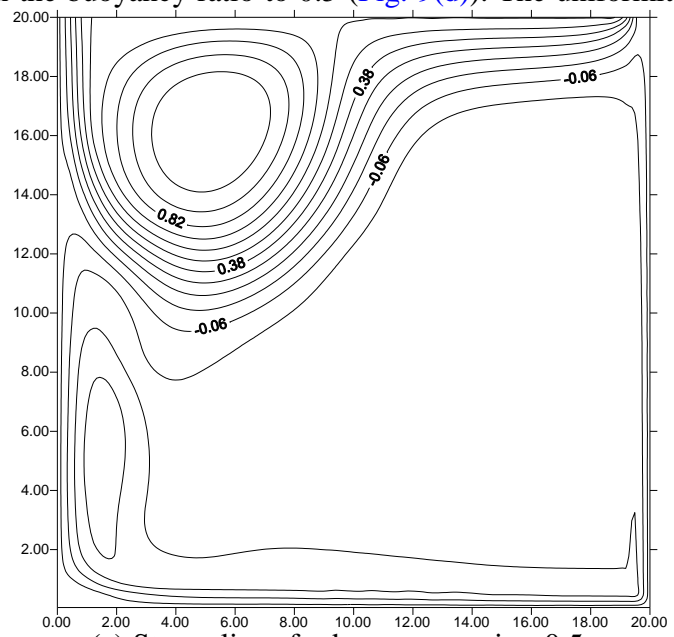

(a) Streamlines for buoyancy ratio $=0.5$

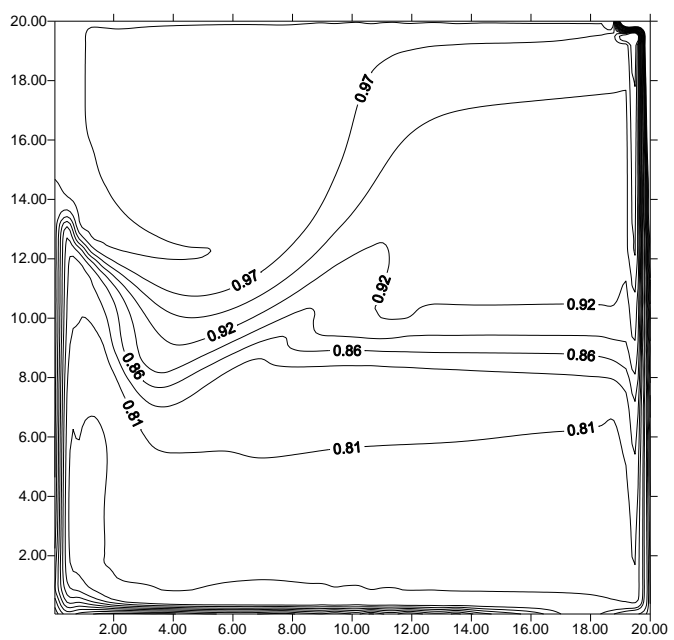

(b) Isotherms for buoyancy ratio $=0.5$ of temperature increases as the value of buoyancy ratio increases.

The comparison of Fig. 9(a) and Fig. 9(d) indicated the similar patterns of heat-lines and streamlines. Lower values of heat function are observed in the occupied zone for higher buoyancy ratios. The streamlines and isotherm pattern of Case III indicates that the variation in the velocity and temperature of incoming air is mostly in the non-occupied zone. The streamline and heat-line contours indicated a better recirculation zone in the occupied region in Case III. Also, temperature variation is lower in the occupied zone in Case III compared to Case I. A comparison of the average Nusselt numbers on the right and left walls is presented in Fig. 10, for Case II and Case I (straight and inclined inlet jet), at $\mathrm{Re}=1000$.

The position of the center of the main clockwiserotating cell at different buoyancy ratios is given in Table 4. The table indicates that with increase in the buoyancy ratio, the center of this vortex moves towards the left wall.

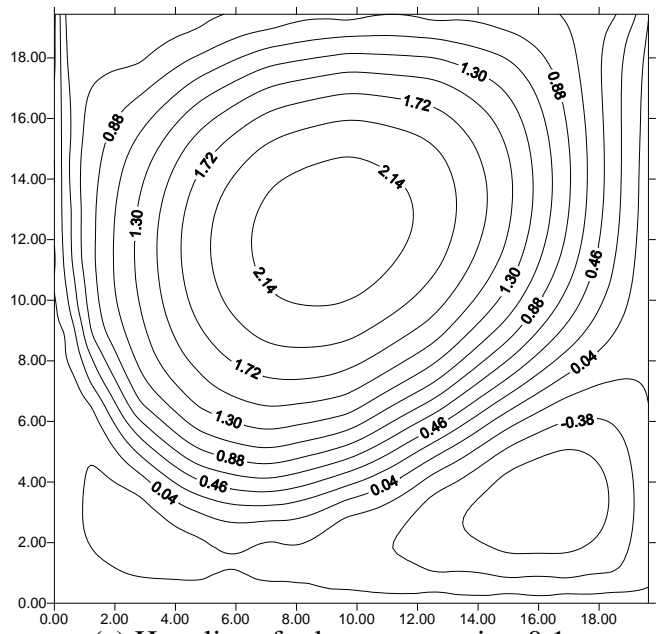

(c) Heat-lines for buoyancy ratio $=0.1$

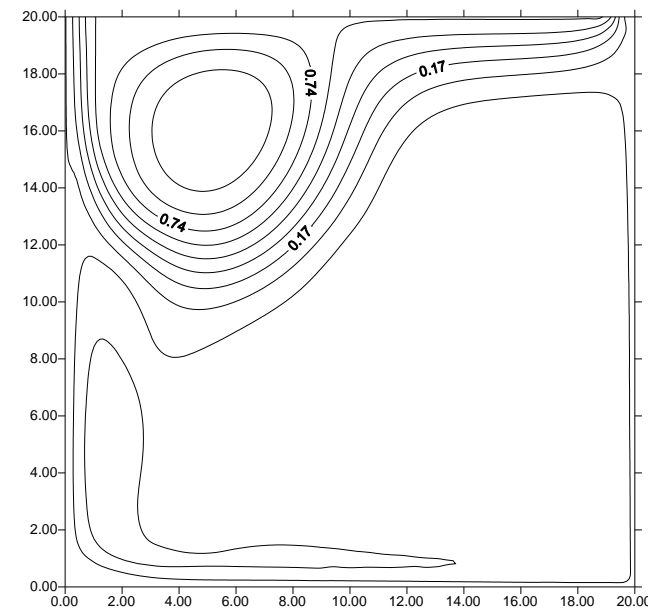

(d) Heat-lines for buoyancy ratio $=0.5$

Fig. 9. Streamline, isotherms and heat-lines for Case III at $\mathrm{Re}=2000$ 


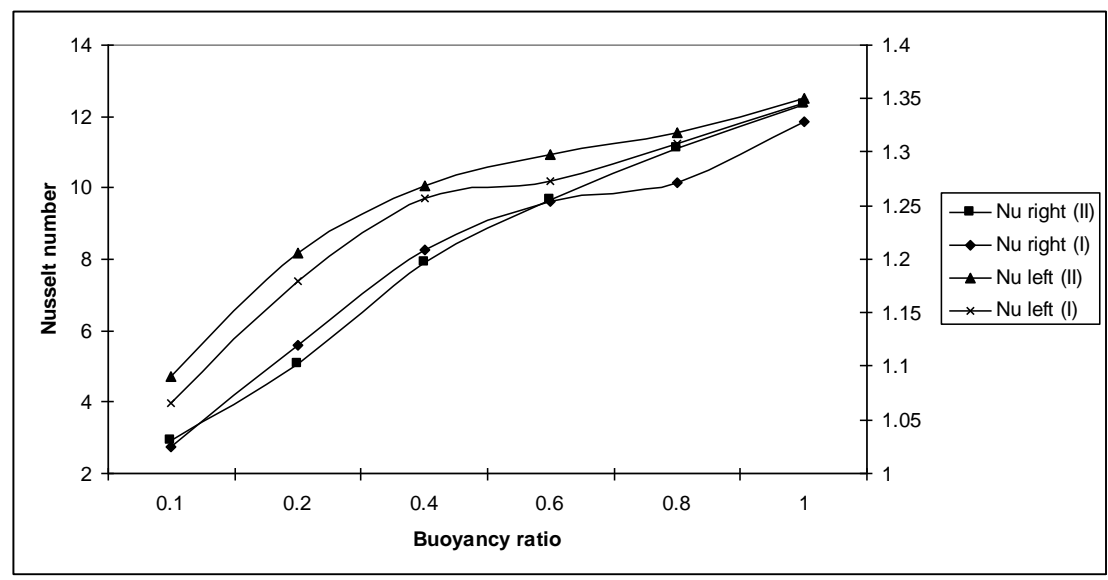

Fig. 10. Comparison of Nusselt numbers on right and left walls for Case I and Case II (Position of outlet on right and left side walls) at $\mathrm{Re}=10$

Table 4 Centre position of main circulating cell for Case III

\begin{tabular}{ccc}
\hline $\begin{array}{c}\text { Buoyancy } \\
\text { ratio }\end{array}$ & $\begin{array}{c}\text { Position of } \\
\text { the cell }(\mathrm{X}, \mathrm{Y}) \\
\text { for } \mathrm{Re}=1000\end{array}$ & $\begin{array}{c}\text { Position of the } \\
\text { cell }(\mathrm{X}, \mathrm{Y}) \text { for } \\
\mathrm{Re}=2000\end{array}$ \\
\hline 0.1 & $9.5,12.25$ & $8.8,11.2$ \\
0.2 & $8.0,12.1$ & $7.5,12.3$ \\
0.4 & $6.8,13.5$ & $6.2,15.6$ \\
0.6 & $6.0,14.0$ & $5.3,16.9$ \\
0.8 & $5.0,14.5$ & $4.4,17.3$ \\
1.0 & $4.0,16.0$ & $3.7,17.7$ \\
2.0 & $2.5,19.0$ & $2.5,18.2$ \\
5.0 & $1.8,19.8$ & $1.6,18.8$ \\
\hline
\end{tabular}

The average Nusselt number on the right wall is plotted on the left Y-axis, while the average Nusselt number on the left wall is plotted on the right Y-axis. It is observed that with increase in the buoyancy ratio, the average Nusselt numbers on both the walls increase. Higher values of the average Nusselt number are obtained for Case II. Therefore, the heat transfer is higher on the right and left walls, for Case II. These values are closer for very high buoyancy ratios. The average Nusselt number on the left and right walls are given in Table 5, for different buoyancy ratios.

Table 5 Variation in the average Nusselt numbers with buoyancy ratios $\left(\mathrm{Gr} / \mathrm{Re}^{2}\right)$, for Case II

\begin{tabular}{cccc}
\hline $\begin{array}{c}\text { Reynolds } \\
\text { number }\end{array}$ & $\begin{array}{c}\text { Buoyancy } \\
\text { ratio } \\
\left(\mathrm{Gr} / \mathrm{Re}^{2}\right)\end{array}$ & $\begin{array}{c}\text { Nusselt } \\
\text { number } \\
\text { at right } \\
\text { wall }\end{array}$ & $\begin{array}{c}\text { Nusselt } \\
\text { number } \\
\text { at left } \\
\text { wall }\end{array}$ \\
\hline \multirow{4}{*}{1000} & 0.1 & 2.92458 & 1.09051 \\
& 0.2 & 5.06887 & 1.20561 \\
& 0.4 & 7.91397 & 1.26927 \\
& 0.6 & 9.67500 & 1.29847 \\
& 0.8 & 11.1008 & 1.31818 \\
& 1.0 & 12.3475 & 1.35037 \\
\hline \multirow{3}{*}{2000} & 0.1 & 3.49232 & 1.65386 \\
& 0.2 & 6.55938 & 1.77813 \\
& 0.4 & 10.5120 & 1.86365 \\
& 0.6 & 12.1275 & 1.91987 \\
& 0.8 & 16.3919 & 1.98599 \\
& 1.0 & 19.9164 & 2.03522 \\
\hline
\end{tabular}

It is also observed that the average Nusselt number on right wall increases with increase in buoyancy ratio. The average Nusselt number on the left wall also increases with increase in buoyancy ratio, but at a slower rate.

It can be predicted from the flow pattern analysis that for ceiling type diffusers, inclination creates a difference in the flow patterns. Uniform distribution of temperature is observed throughout the occupied zone at higher buoyancy ratios. This is due to the inclined division of incoming air into several air streams after entering from the inlet. The left part of incoming air stream is attached with the ceiling while right part of the incoming air stream is attached with the right side wall. At very low buoyancy ratios and low Reynolds number, the incoming air stream is weaker and hence, does not reach the occupied region due to poor recirculation. But at higher buoyancy ratio, the circulation is uniform throughout the room and covers most of the area of the room.

\section{CONClusions}

The plots of streamlines, isotherms and heat-lines indicates that best results are obtained if the inlet air-jet from the ceiling diffuser is diffused at varying angles to the vertical, rather than injecting the air vertically. Three different configurations of ceiling diffusers for inclined inlet jet have been tested, with different outlet positions for same room dimensions. Comparisons of these cases show that Case I is the optimum configuration, as the temperature distribution in the occupied zone has least variation for this case. Also, the velocity distribution is almost uniform in most of the occupied zone.

The results obtained for Case I, II and III are compared to find the effect of inclination at inlet on room airflow patterns. For inclined inlet, the main air-stream does not move along the floor. With increase in buoyancy ratios, recirculation, uniformity of temperature and velocity in the occupied zone increases. The main circulating cell moves towards the left wall. The uniformity of temperature in the occupied zone is higher for the different configurations of room airflow simulations. 
As the buoyancy increases, the streamlines takes almost circular shape throughout the room, for Case I, and become almost symmetric about the center of the room. Velocities and temperature are higher in boundary-layer regions near the walls. At higher $\mathrm{Re}$ and lower buoyancy ratio, fresh air travels a long distance from inlet to outlet touching all the walls of the room. It increases the freshness and cleanness inside the occupied zone. The Nusselt number shows steep variations for lower buoyancy ration, whereas the difference is less prominent at higher Buoyancy ratios.

\section{ACKNOWLEDGEMENT}

Authors are thankful to the guidance provided by Late Prof. R. C. Arora and IIT Kharagpur for their continuous support.

\section{REFERENCES}

Abe, K., T. Kondoh and Y. Nagano (1995). A New Turbulence Model for Predicting Fluid Flow and Heat Transfer in Separating and Reattaching FlowsII. Thermal Field Calculations, Int. J. Heat Mass Transfer. 38(8), 1467-1481.

Aubert, A. and C. Solliec (2011). Push-Pull Air Curtain Performances for VOCs Containment in an Industrial Process, Journal of Applied Fluid Mechanics, 4(1), 43-50.

Awbi, H.B. and A.A. Setrak A.A. (1986). Numerical Solution of Ventilation Air Jet, $5^{\text {th }}$ Int. Symposium on use of Computers for Environmental Engineering Related To Buildings, Bath. 236-246.

Awbi, H.B. and A.A. Setrak (1987). Air Jet Interference Due to Ceiling-Mounted Obstacles, Proc. of the International conference on Air Distribution in ventilated spaces, Stockholm. 12-23.

Awbi, H.B. (1989). Application of Computational Fluid Dynamics in Room Ventilation, Building and Environment. 241, 73-84.

Calmidi, V.V. and R.L. Mahajan (1999). Mixed Convection over a Heated Horizontal Surface in a Partial Enclosure, Int. J. Heat and Fluid Flow. 19, 358-367.

Chen Q., A. Moser and A. Huber (1990). Prediction of Buoyant, Turbulent Flow by a Low-ReynoldsNumber k- $\square$ Model, ASHRAE Trans. 96(1), 564573.

Chen, Q. and Z. Jiang (1992). Evaluation of air supply method in a classroom with a low ventilation rate, Proceedings of the Jacques Cartier Conference, Montreal, Canada. 98-102.
Chen, Q. , A. Moser and P. Suter (1992). A Numerical Study of Indoor Air Quality and Thermal Comfort under Six Kinds of Air Diffusion, ASHRAE Trans. 98(1), 203-217.

Davidson, L. and P.V. Nielsen (1998). A study of laminar backward facing step flow, Dept. of building technology and structural engineering, Aalborg University, Denmark. 1-34.

Einberg, G. and S. Holmberg (2003). Particle removal efficiency in a numerical test room, 4th international symposium on HVAC, Beijing, China. 2003, 123-129.

Gladstone, C. and A. Woods (2000). On the application of box models to particle-driven gravity currents, Journal of fluid mechanics. 416, 187-195.

Gladstone, C. and A. Woods (2001). On buoyancy driven natural ventilation of a room with a heated floor, Journal of fluid mechanics. 441, 293-314.

Hsu, T.H., P.T. Hsu and S.P. How (1997). Mixed convection in a partially divided rectangular enclosure, Numerical heat transfer, Part A. 31, 655683.

Hu S.C., Barber J.M. and Chuah Y.K. (2004). A CFD study for cold air distribution systems, ASHRAE transactions. Part 1, 614-627.

Kameel R. and Khalil E. (2004). Prediction of flow, turbulence, heat transfer and humidity patterns in operating theatres, IECEC-2004, 23-34.

Kato S. and Murakami S. (1985). Three-dimensional numerical simulation of turbulent airflows in ventilated room by means of 2-equation model, International Symposium on CFD, Tokyo. 560-571.

Kato S., Murakami S. and Nagano S. (1992). Numerical study on diffusion in a room with a locally balanced supply exhaust airflow rate system, ASHRAE transactions. 98(I), 338-349.

Kao H. M., Chang T.J., Hsieh Y.F., Wang C.H. and Hsieh C.I. (2009). Comparison of airflow and particulate matter transport in multi-room buildings for different natural ventilation patterns, Energy and Buildings, 41, 966-974.

Kimura, S., and Bejan, A., (1983). The Heatline Visualization of Convective Heat Transfer, ASME J. Heat Transfer, 105, 916-919. 
Lage, J.L., A. Bejan and R. Anderson (1992). Removal of Contaminant Generated by a Discrete Source in a Slot Ventilated Enclosure, Int. J. Heat Mass Transfer. 355, 1169-1180.

Lage, J.L., A. Bejan and R. Anderson (1991). Efficiency of Transient Contaminant Removal from a Slot Ventilated Enclosure, Int. J. Heat Mass Transfer. 3410, 2603-2615.

Lam, C.K.G. and K. Bremhorst (1981). A modified form of the $\mathrm{k}-\varepsilon$ model for predicting wall turbulence. Transactions of the ASME. 103, 456460.

Lim, E., T. Yamanaka, H. Kotani, Y. Momoi and K. Sagara (2009). Influence of Supply and Natural Ventilation Openings on Airflow Characteristics in Office Room with Hybrid Air-conditioning System, Proceedings of ROOMVENT 2009, 1783-1790.

Lin, Y.J.P. and P.F. Linden (2004). A model for under floor air distribution system, Energy and building. 43(4), 434-440.

Lin, Z., L. Tian, T. Yao, Q. Wang and T.T. Chow (2011). Experimental and numerical study of room airflow under stratum ventilation, Building and Environment, 46, 235-244.

Mendez, C., J.F. San Jose , J.M. Villafruela and F. Castro (2008). Optimization of a hospital room by means of CFD for more efficient ventilation, Energy and Buildings, 40, 849-854.

Murakami, S., S. Kato and Y. Suyama (1989). Numerical study on diffusion field as affected by arrangement of supply and exhaust openings in conventional flow type clean room, ASHRAE Transactions. 100(2), 787-795.

Nielsen, P.V. (1990). Specification of a TwoDimensional Test Case, International Energy Agency, Energy Conservation in Buildings and Community Systems, Annex 20: Air Flow Pattern Within Buildings, ISSN 0902-751. R9040, 1-15.

Nielsen, P.V., A. Restivo and J.H. Whitelaw (1978). The Velocity Characteristics of Ventilated Room, Journal of Fluid Engineering. 100, 291-298.

Patankar, S.V. (1980). Numerical Heat Transfer and Fluid Flow, McGraw Hill, Washington.

Patel, V.C., W. Rodi and G. Scheuerer (1985). Turbulence models for near wall and low Reynolds number flows: a review, AIAA Journal. 239-247.
Reinartz, A. and U. Renz (1984). Calculations of the Temperature and Flow Field in Room Ventilated by a Radial Air Distributor, Int. J. Refrigeration. 7, 308-312.

Sinha, S.L.(2000). Numerical simulation of room airflow, $P h D$ thesis, IIT Kharagpur;2000

Srebric, J., V. Vukovic, G. He and X. Yang (2008). CFD boundary conditions for contaminant dispersion, heat transfer and airflow simulations around human occupants in indoor environments, Building and Environment, 43, 294-303.

Su, M., Q. Chen and C.M.Chiang (2001). Comparison of different sub-grid scale models of large eddy simulation for indoor airflow modeling, Journal of Fluid Engineering. 123, 628-638.

Sun, Y. and T.F. Smith (2005). Airflow characteristics of a room with square cone diffusers, Building and environment. 40, 589-600.

Svidt, K., B. Bjerg and T.D. Nielsen (2004). Initial studies on virtual reality visualization of 3D airflow in ventilated livestock buildings, Conference on Chalmers AVR II and CONVR. 37-44.

Tripathi, B., R.C. Arora and S. Ghosh Moulic (2004)a. Buoyancy Effects on the Air Movement Inside a Room, Proceedings of the 31st National conference on fluid mechanics \& fluid power NCFMFP, Jadavpur University, Kolkata, India. 805-811.

Tripathi, B., R.C. Arora and S. Ghosh Moulic (2004)b. Effect of buoyancy on room air flow, Proceedings of Heat Transfer/Fluids Engineering Summer Conference HTFED2004, North Carolina, USA. 1333-1338.

Tripathi, B., R.C. Arora and S. Ghosh Moulic (2005). Prediction of Flow Behavior on Diffuser Angle in an Enclosure, Proceedings of 2005 ASME Fluids Engineering Division Summer Meeting and Exhibition FEDSM2005, TX, USA. 647-650.

Van Doormaal, J.P, G.D. Raithby (1984). Enhancements of the SIMPLE method for predicting, Numerical Heat Transfer, 7, 147-163.

Williams, P.T., A.J. Baker and R.M. Kelso (1994). Numerical calculation of room air motion-part 2: the continuity constraint finite element method for three-dimensional incompressible thermal flows, ASHRAE transactions. 100I, 531-548. 
B. Tripathi et al. / JAFM, Vol. 5, No. 4, pp. 1-12, 2012.

Williams, P.T., A.J. Baker and R.M. Kelso (1994). Numerical calculation of room air motion-part 3: three-dimensional CFD simulation of a full scale room air experiment, ASHRAE transactions. 100I, 549-564.

Xu, W. and Q. Chen (2001)a. A two layer turbulence model for simulating indoor airflow part I. model development, Energy and building. 33, 613-625.

Xu, W. and Q. Chen (2001)b. A two-layer turbulence model for simulating indoor airflow part II. Applications, Energy and building. 33, 627-63. 